\title{
Supplementation of Omega 3 during Pregnancy and the Risk of Preterm Birth: A Systematic Review and Meta-Analysis
}

\author{
Ramón Serra ${ }^{1, \dagger}$, Reyna Peñailillo ${ }^{2,+}{ }^{+}$, Lara J. Monteiro ${ }^{2}$, Max Monckeberg ${ }^{2}$, Macarena Peña ${ }^{2}$, Lía Moyano ${ }^{2}$, \\ Camila Brunner ${ }^{2}{ }^{\mathbb{D}}$, Georgina Vega ${ }^{2}$, Mahesh Choolani ${ }^{3,4}$ and Sebastián E. Illanes ${ }^{2, *}$ \\ 1 Hospital FF.AA Cirujano Guzmán, Punta Arenas 6212631, Chile; rserratagle@yahoo.com \\ 2 Department of Obstetrics, Gynecology and Laboratory of Reproduction, Universidad de los Andes, \\ Santiago 7620001, Chile; rpenailillo@uandes.cl (R.P.); lmonteiro@uandes.cl (L.J.M.); \\ mmonckebergz@uandes.cl (M.M.); mspena@miuandes.cl (M.P.); lgmoyano@miuandes.cl (L.M.); \\ cpbrunner@miuandes.cl (C.B.); gsvega@miuandes.cl (G.V.) \\ 3 Department of Obstetrics \& Gynaecology, Yong Loo Lin School of Medicine, National University of \\ Singapore, Singapore 119228, Singapore; obgmac@nus.edu.sg \\ 4 Department of Obstetrics \& Gynaecology, National University Hospital, Singapore 119228, Singapore \\ * Correspondence: sillanes@uandes.cl \\ + These authors contributed equally to this work.
}

Citation: Serra, R.; Peñailillo, R.; Monteiro, L.J.; Monckeberg, M.; Peña, M.; Moyano, L.; Brunner, C.; Vega, G.; Choolani, M.; Illanes, S.E.

Supplementation of Omega 3 during Pregnancy and the Risk of Preterm Birth: A Systematic Review and Meta-Analysis. Nutrients 2021, 13, 1704. https://doi.org/10.3390/ nu13051704

Academic Editor:

Ann-Sofie Sandberg

Received: 10 April 2021

Accepted: 10 May 2021

Published: 18 May 2021

Publisher's Note: MDPI stays neutral with regard to jurisdictional claims in published maps and institutional affiliations.

Copyright: (C) 2021 by the authors Licensee MDPI, Basel, Switzerland. This article is an open access article distributed under the terms and conditions of the Creative Commons Attribution (CC BY) license (https:// creativecommons.org/licenses/by/ $4.0 /)$.

\begin{abstract}
Preterm birth (PTB) is a major cause of neonatal death and long-term consequences for the newborn. This review aims to update the evidence about the potential benefit of pharmacological supplementation with omega 3 fatty acids during pregnancy on the incidence of PTB. The Medline, Embase, Cochrane Library and Central databases were searched until 28 June 2020 for RCTs in which omega 3 supplementation was used versus placebo to reduce PTB risk. Data from 37 trials were analyzed. We found an 11\% reduction in PTB risk (RR(risk ratios), 0.89; 95\% CI (confidence intervals), 0.82 to 0.97 ) in trials using omega 3 supplements versus placebo. Regarding early PTB (ePTB), there was a $27 \%$ reduction in the risk of ePTB (RR, $0.73 ; 95 \%$ CI, 0.58 to 0.92$)$. However, after sensitivity analyses, there were no significant differences in PTB and ePTB risk (PTB RR, 0.92; 95\% CI, 0.83 to 1.01 , ePTB RR, $0.82 ; 95 \% \mathrm{CI}, 0.61$ to 1.09 ). We conclude that omega 3 supplementation during pregnancy does not reduce the risk of PTB and ePTB. More studies are required to determine the effect of omega 3 supplementations during pregnancy and the risk of detrimental fetal outcomes.
\end{abstract}

Keywords: omega 3 supplementation; preterm birth; meta-analysis

\section{Introduction}

Preterm birth (PTB), defined as birth $<37$ weeks of gestational age (GA), has been estimated to affect one in nine infants worldwide and represents the most significant cause of neonatal death [1]. Likewise, early PTB (ePTB, birth $<34$ weeks of GA) also represents a high risk of heart failure, infections and neonatal mortality [2]. Additionally, women who give birth before 37 weeks of GA have an increased risk of preterm deliveries in their second pregnancies [3]. Many strategies have been used to reduce the risk of PTB, particularly, the use of progesterone and cervical cerclage, which have limitations such as cost, availability and safety [4]. One strategy focused on the prevention of PTB is the administration of long-chain polyunsaturated fatty acids (LCPUFA) during pregnancy, which is accessible and cheap and has minimal side effects.

Omega 3 LCPUFA, including eicosapentaenoic acid (EPA) and docosahexaenoic acid (DHA), are essential in metabolic and physiological processes during embryonic and fetal development [5]. Although higher intakes of DHA and EPA's have been recommended worldwide, Dietary Reference Intakes (DRIs) have not been established. The Institute of Medicine (IOM) recommends that the intake of EPA and DHA contributes to 10 percent of the total omega 3 fatty acid intake (160 mg per day approximately) [6]. In the case of the 
Food and Agriculture Organization (FAO), the recommendation is an intake of $200 \mathrm{mg} /$ day of DHA during pregnancy [7].

Lower plasma levels of omega 3 LCPUFAs during pregnancy have been associated with detrimental perinatal outcomes, such as preterm delivery [8] and preeclampsia [9]. However, until now, there is no consensus on whether omega 3 supplementation during pregnancy reduces the risk of prenatal complications. A significant number of studies have been carried out to address this topic, including randomized controlled trials (RCTs) and meta-analyses. Some of them have shown a significant association between the consumption of fish or DHA supplements in pregnancy and decreased PTB incidence [10-12], but others have failed to demonstrate this association [13]. In 2010, Makrides et al. conducted an RCT to evaluate the impact of DHA supplementation during pregnancy on maternal depression and concluded that the consumption of DHA was associated with a decrease in the incidence of ePTB compared to the control group [14]. However, this outcome was secondary, and the analyses were not adjusted for multiplicity, limiting the confidence in the results. Olsen et al. showed in an RCT that fish oil does not prevent PTB in Chinese women; however, it is important to consider that supplementation started at midgestation [15]. Among the mechanisms suggested to explain the effect of omega 3 on PTB are the production of eicosanoids involved in the parturition process [16] and their role in the inflammatory pathway, including an increase in resolving R3 production $[17,18]$. Besides its tocolytic properties, omega 3 may also have an effect on the electrical activity of the myometrium during the pre-labor period, demonstrating an antiarrhythmic effect that could explain the role of omega 3 in the prevention of PTB [19].

The primary outcome of this systematic review and meta-analysis is to update the evidence in order to evaluate the potential benefit of pharmacological supplementation with omega 3 fatty acids during pregnancy in the incidence of PTB. We also review the current evidence in order to analyze the potential impact of this supplementation on other perinatal outcomes.

\section{Materials and Methods}

The systematic review and meta-analysis were conducted according to the Cochrane Handbook for Systematic Reviews of Interventions [20].

\subsection{Eligibility Criteria}

The eligibility criteria comprised of RCTs including patients of any age with single or multiple pregnancies, with or without known pathology, and comparing the use of omega 3 fatty acid supplements versus placebo or no intervention, or the use of omega 3 acid supplements in combination with another agent versus placebo or no intervention.

\subsection{Outcomes}

The primary outcome was preterm delivery $<37$ weeks of gestation; the secondary outcomes included early preterm delivery $<34$ weeks of gestation, preeclampsia, intrauterine growth restriction (IUGR), fetal death in utero and neonatal death.

\subsection{Literature Search and Selection of Studies}

The search was conducted until 28 June 2020. We searched the following electronic databases: the Cochrane Central Register of Controlled Trials (CENTRAL), the Cochrane Library, MEDLINE (PubMed) and Embase. Moreover, we manually searched for relevant journals, conference proceedings and reference lists. We did not restrict the search by language, date, or publication status in order to reduce publication and retrieval bias.

\subsection{Data Collection}

Two reviewers (R.S. and S.E.I.) independently assessed the results of the electronic search. First, we identified duplicate articles in electronic databases, as well as duplicate articles in different journals. We then identified and selected potentially eligible studies 
based on title and then abstract. Potentially eligible studies were retrieved and thoroughly reviewed independently by two reviewers (R.S. and S.E.I.). Those studies that met the selection criteria were included in the review. Differences were resolved by discussion between the two reviewers. The two reviewers (R.S. and S.E.I.) then extracted data from selected studies to be analyzed with Review Manager 5.4 software.

\subsection{Risk of Bias}

Two review authors (R.S. and S.E.I.) independently assessed the risk of bias of each included study. Disagreements were resolved by discussion or consultation with one of the other authors. To assess the risk of bias, we used the criteria recommended by the Cochrane Collaboration [20]: random sequence generation, allocation concealment, blinding of participants and personnel, blinding of outcome assessment, incomplete outcome data, selective reporting and other (analysis for intention to treat and compliance). Each of these criteria was classified as low risk, high risk or uncertain risk of bias. Regarding the blinding of outcome assessment, we considered it a low risk only if the trial described how the outcome measurement was concealed. If it was only stated in the article that this was a double-blind RCT, we considered it an uncertain risk. Regarding the incomplete outcome data, we considered the trial to be of low risk only if the losses were less than $15 \%$; between $15 \%$ and $20 \%$, the trial was considered to be of low uncertain risk; and for over $20 \%$ of losses, the trial was considered to have a high risk of bias.

\subsection{Statistical Analyses}

Statistical analyses were performed using Review Manager 5.4 software. Considering that all the outcomes analyzed in our review are dichotomous, we calculated the risk ratios (RR) and the $95 \%$ confidence intervals $(95 \% \mathrm{CI})$ for each outcome. For trials with more than two arms, we combined groups to make a single pairwise comparison. As far as possible, we tried to include all participants who were randomized in the denominator of each analysis, and each participant was analyzed in the group to which they were assigned regardless of whether or not they received the intervention, thus following the intention-totreat principle. Heterogeneity was assessed using the $\mathrm{chi}^{2}$ and $\mathrm{I}^{2}$ statistics. We considered heterogeneity as important if $\mathrm{I}^{2}$ was greater than $30 \%$ or the value of $p$ associated with chi $^{2}$ was $<0.05$. If the heterogeneity was significant, the meta-analyses were performed with random effect models; otherwise, we used fixed-effect models. When the meta-analyses included ten or more trials, we investigated publication biases using funnel plots, visually assessing the skewness of the plots. We performed sensitivity analyses to explore the effect of trial quality on different outcomes. The sensitivity analysis was performed, including those articles rated with low risk of bias for the following domains: sequence generation and concealment of allocation, and inadequate blinding.

\section{Results}

The search for trials was carried out during June 2020. Three electronic databases were reviewed: in Central, 574 potentially eligible articles were found; 909 articles were found in Embase; and 1224 articles were found in PubMed Medline. The search strategies are summarized in Table S1, Supplementary Materials. Four articles emerged from the search carried out in relevant journals, conference proceedings and reference lists.

After deleting duplicate articles and screening them for inclusion in the current review based on title and abstract, 97 articles were obtained, which were extensively reviewed. Finally, only 37 articles met the selection criteria and were incorporated into this review. Among the exclusion criteria were the outcomes analyzed that did not relate with the research question, incomplete or inadequate protocols and secondary analysis. The selection process of the included trials is summarized in Figure 1, and their characteristics in Table S2, Supplementary Materials. 


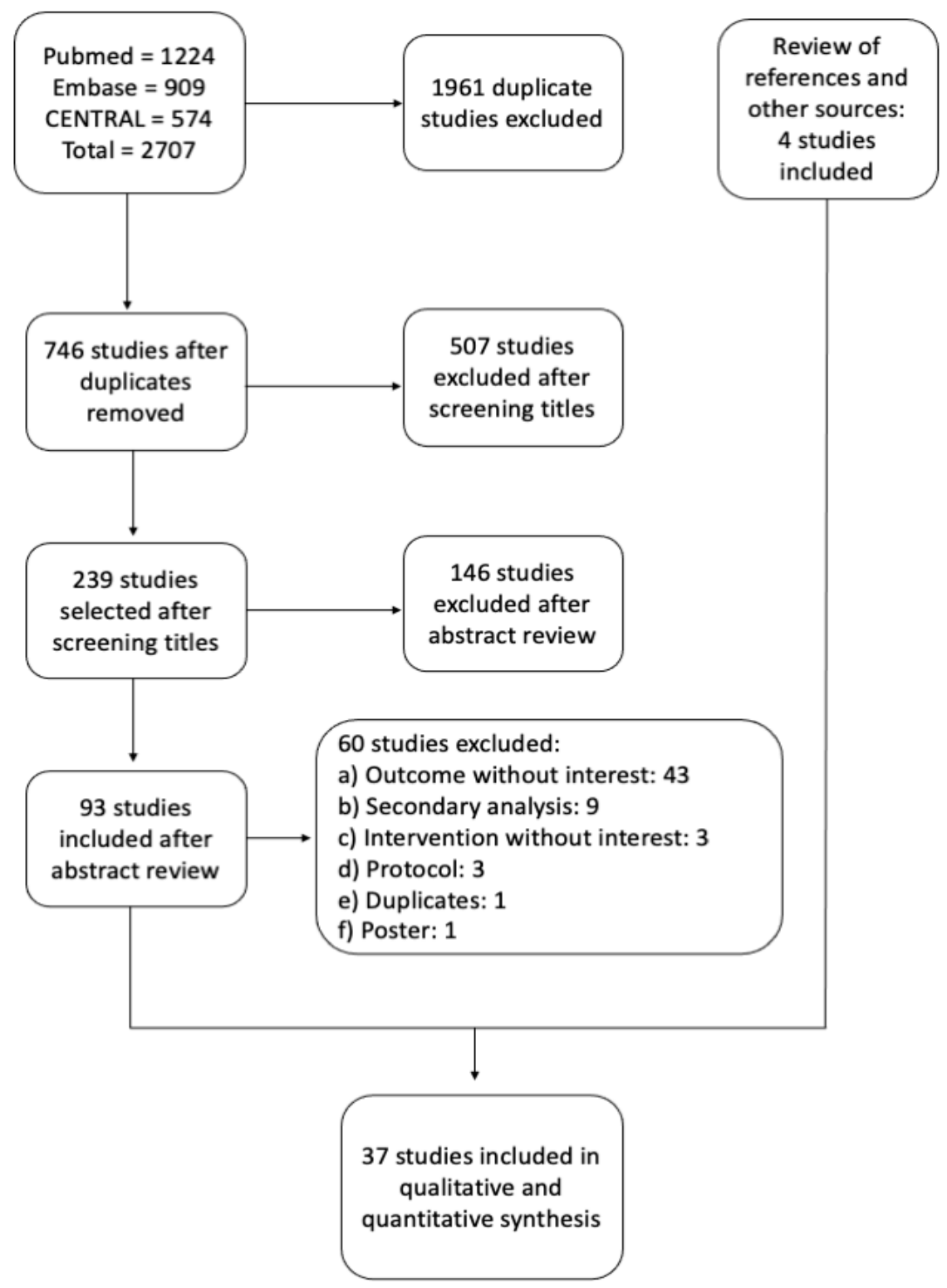

Figure 1. Flow chart of the selection process of randomized controlled trials included in this metaanalysis.

\subsection{Main Outcome: Preterm Birth Less Than 37 Weeks}

In our review, 31 trials were found in which the effect of omega 3 supplements versus placebo or versus compounds without omega 3 was compared to the rate of PTB. The review included 21,458 patients: the experimental group included 11,603 participants, of whom 939 had a PTB, and the control group included 9855 participants, of whom 994 had a PTB (Figure 2). According to these results, there was an 11\% reduction in the risk of PTB (RR, $0.89 ; 95 \%$ CI, 0.82 to 0.97 ). Some asymmetry was observed in the funnel plot's visual evaluation for this outcome, suggesting the absence of small studies with negative results (Figure 3). Heterogeneity was not significant $\left(\mathrm{I}^{2}=0 \% p\right.$ associated with $\left.\mathrm{chi}^{2}=0.58\right)$. 


\begin{tabular}{|c|c|c|c|c|c|c|c|c|c|}
\hline Study or Subgroup & \multicolumn{2}{|c|}{ omega 3} & \multicolumn{2}{|c|}{ no omega 3} & \multicolumn{2}{|r|}{ Risk Ratio } & \multicolumn{2}{|c|}{$\begin{array}{c}\text { Risk Ratio } \\
\text { M-H, Fixed, 95\% Cl }\end{array}$} & \\
\hline Bisgard 2016 & 15 & 365 & 18 & 371 & $1.8 \%$ & $0.85[0.43,1.65]$ & & - & \\
\hline Borod 1999 & 6 & 37 & 4 & 16 & $0.6 \%$ & $0.65[0.21,1.99]$ & & & \\
\hline Bulstra-Ramakers 1994 & 8 & 32 & 10 & 31 & $1.0 \%$ & $0.78[0.35,1.70]$ & & - & \\
\hline Carlson 2013 & 12 & 154 & 13 & 147 & $1.3 \%$ & $0.88[0.42,1.87]$ & & & \\
\hline Dilli 2017 & 6 & 52 & 9 & 68 & $0.8 \%$ & $0.87[0.33,2.29]$ & & & \\
\hline Farshbaf-Khalili 2016 & 3 & 75 & 4 & 75 & $0.4 \%$ & $0.75[0.17,3.24]$ & & & \\
\hline Harper 2010 & 167 & 434 & 174 & 418 & $17.5 \%$ & $0.92[0.78,1.09]$ & & & \\
\hline Hauner 2012 & 3 & 92 & 4 & 96 & $0.4 \%$ & $0.78[0.18,3.40]$ & & & \\
\hline Helland 2001 & 1 & 301 & 2 & 289 & $0.2 \%$ & $0.48[0.04,5.27]$ & & & \\
\hline Horvaticek 2017 & 4 & 51 & 4 & 47 & $0.4 \%$ & $0.92[0.24,3.48]$ & & & \\
\hline Jamilian 2018 & 0 & 20 & 1 & 20 & $0.1 \%$ & $0.33[0.01,7.72]$ & & & \\
\hline Makrides 2010 & 67 & 1197 & 88 & 1202 & $8.6 \%$ & $0.76[0.56,1.04]$ & -1 & & \\
\hline Makrides 2019 & 211 & 2734 & 246 & 2752 & $24.1 \%$ & $0.86[0.72,1.03]$ & & & \\
\hline Malcom 2003 & 0 & 31 & 1 & 32 & $0.1 \%$ & $0.34[0.01,8.13]$ & & & \\
\hline Mardones 2007 & 22 & 493 & 32 & 477 & $3.2 \%$ & $0.67[0.39,1.13]$ & & & \\
\hline Miller 2016 & 3 & 60 & 10 & 55 & $1.0 \%$ & $0.28[0.08,0.95]$ & & & \\
\hline Min 2014 & 8 & 60 & 15 & 57 & $1.5 \%$ & $0.51[0.23,1.10]$ & & & \\
\hline Min 2016 & 12 & 58 & 5 & 56 & $0.5 \%$ & $2.32[0.87,6.15]$ & & & \\
\hline Olsen 1992 & 9 & 266 & 15 & 267 & $1.5 \%$ & $0.60[0.27,1.35]$ & & - & \\
\hline Olsen 2000 & 152 & 394 & 167 & 403 & $16.3 \%$ & $0.93[0.79,1.10]$ & & & \\
\hline Olsen 2019 & 96 & 3401 & 50 & 1717 & $6.5 \%$ & $0.97[0.69,1.36]$ & & - & \\
\hline Onwude 1995 & 21 & 113 & 19 & 119 & $1.8 \%$ & $1.16[0.66,2.05]$ & & & \\
\hline Pellonperä 2019 & 15 & 191 & 7 & 188 & $0.7 \%$ & $2.11[0.88,5.06]$ & & & \\
\hline Ramakrishnan 2010 & 49 & 487 & 40 & 486 & $3.9 \%$ & $1.22[0.82,1.82]$ & & & \\
\hline Razavi 2017 & 0 & 60 & 1 & 60 & $0.1 \%$ & $0.33[0.01,8.02]$ & & & \\
\hline Smuts 2003_1 & 14 & 142 & 17 & 149 & $1.6 \%$ & $0.86[0.44,1.69]$ & & - & \\
\hline Smuts 2003_2 & 1 & 18 & 5 & 19 & $0.5 \%$ & $0.21[0.03,1.64]$ & & 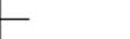 & \\
\hline Soldo 2018 & 0 & 45 & 1 & 45 & $0.1 \%$ & $0.33[0.01,7.97]$ & & & \\
\hline Taghizadeh 2016 & 3 & 29 & 2 & 30 & $0.2 \%$ & $1.55[0.28,8.62]$ & & & \\
\hline Tofail 2006 & 30 & 125 & 27 & 124 & $2.7 \%$ & $1.10[0.70,1.74]$ & & & \\
\hline Van Goor 2009 & 1 & 86 & 3 & 39 & $0.4 \%$ & $0.15[0.02,1.41]$ & & & \\
\hline Total (95\% Cl) & & 11603 & & 9855 & $100.0 \%$ & $0.89[0.82,0.97]$ & & & \\
\hline Total events & 939 & & 994 & & & & & & \\
\hline $\begin{array}{l}\text { Heterogeneity: } \mathrm{Chi}^{2}=27 \\
\text { Test for overall effect: } Z\end{array}$ & $\begin{array}{l}3, \mathrm{df}=3 \\
2.77(\mathrm{P}=\end{array}$ & $\begin{array}{l}(P=0 \\
0.006)\end{array}$ & $.58) ; 1^{2}=$ & $=0 \%$ & & & $\begin{array}{c}1 \\
0.1\end{array}$ & Favours [co & 10 \\
\hline
\end{tabular}

Figure 2. Forest plot of comparison: omega 3 vs. no omega 3, outcome: preterm birth < 37 weeks of gestation.

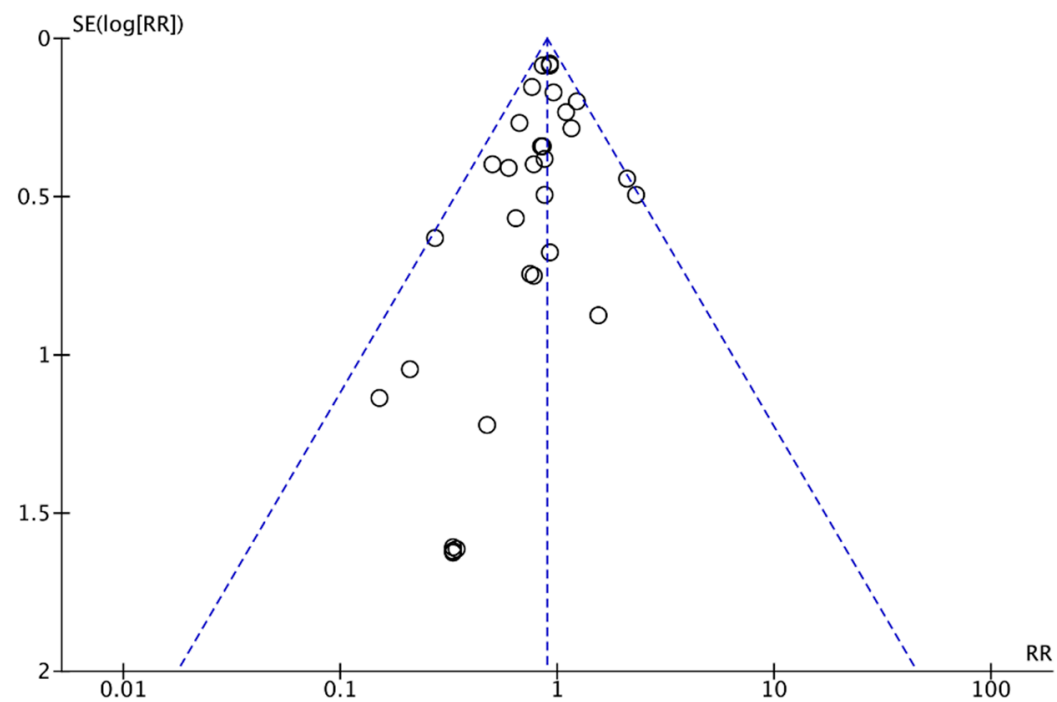

Figure 3. Funnel plot of comparison: omega 3 vs. no omega 3, outcome: preterm birth < 37 weeks of gestation.

\subsection{Secondary Outcomes}

\subsubsection{Early Preterm Delivery}

We found 11 trials comparing the effect of omega 3 supplements versus placebo or compounds without omega 3 on the rate of early PTB (ePTB). The review included 10,864 patients: the experimental group included 5488 participants, of whom 133 had 
ePTB, and the control group included 5376 participants, of whom we found that 176 had ePTB (Figure 4). According to these results, there was a $27 \%$ reduction in the risk of ePTB (RR, $0.73 ; 95 \% \mathrm{CI}, 0.58$ to 0.92 ). Some asymmetry was observed in the funnel plot's visual evaluation for this outcome, suggesting the absence of some studies with negative results (Figure 5). Heterogeneity was significant $\left(\mathrm{I}^{2}=48 \% p\right.$ associated with $\left.\mathrm{chi}^{2}=0.05\right)$.

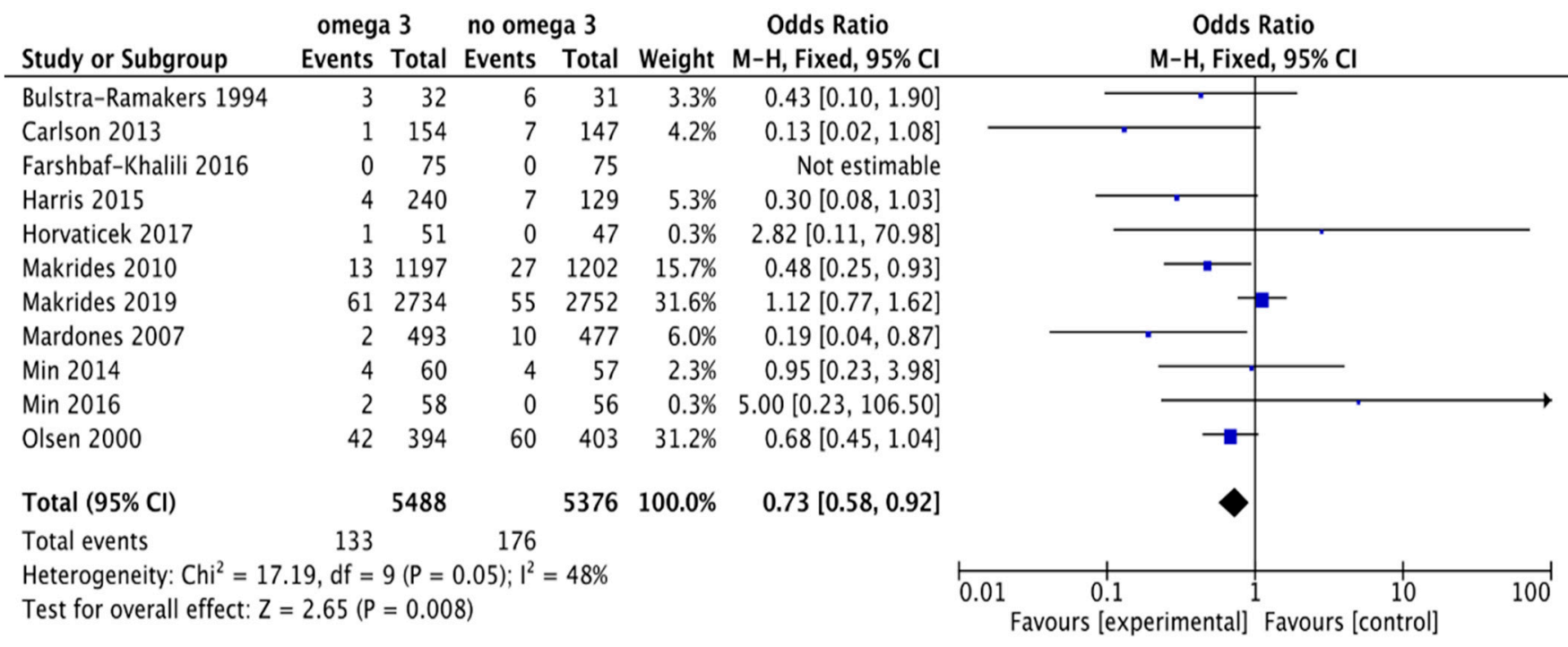

Figure 4. Forest plot of comparison: omega 3 vs. no omega 3, outcome: early preterm birth < 34 weeks of gestation.

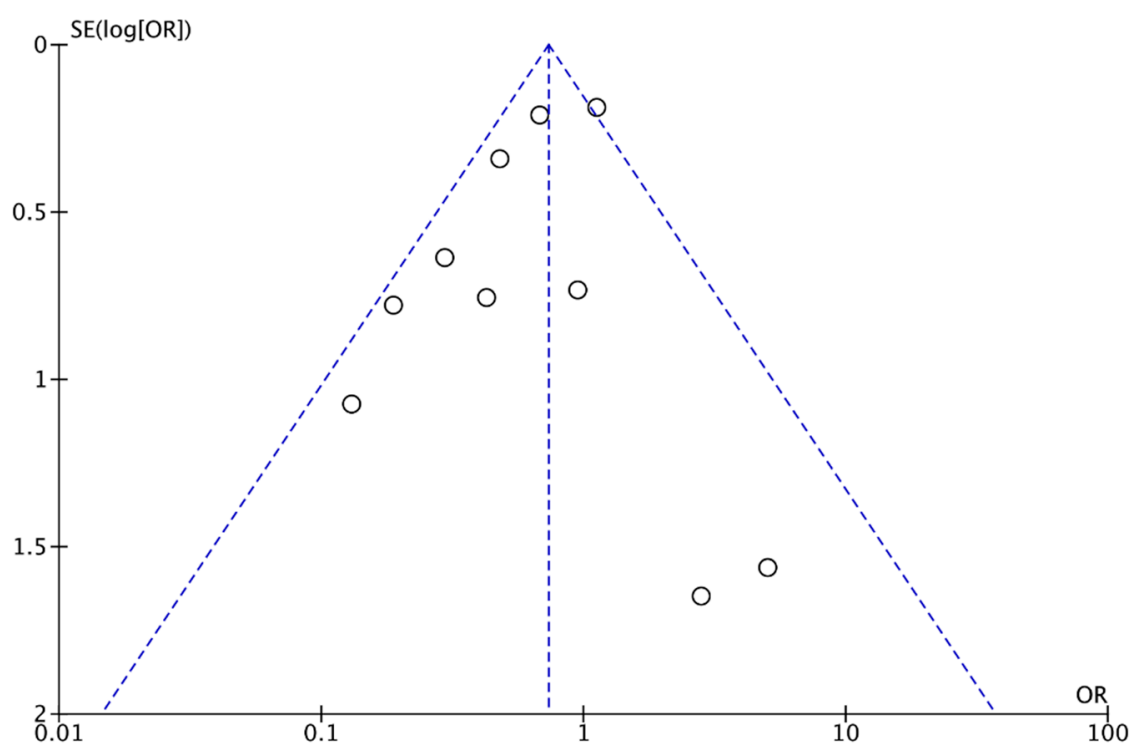

Figure 5. Funnel plot of comparison: omega 3 vs. no omega 3, outcome: early preterm birth < 34 weeks of gestation.

\subsubsection{Preeclampsia or Pregnancy-Induced Hypertension}

We found 19 trials that compared the effect of omega 3 supplements versus placebo or versus compounds without omega 3 on the rate of preeclampsia or pregnancy-induced hypertension (PIH). The review included 11,219 patients: the experimental group included 5643 participants, of whom 391 had preeclampsia or PIH, and the control group included 5576 participants, of whom we found that 390 had preeclampsia or PIH (Figure S1, Supplementary Materials). According to these results, there were no differences in the risk of preeclampsia or PIH (RR, 1.00; 95\% CI, 0.87 to 1.16 ). No asymmetry was observed in 
the funnel plot's visual evaluation for this outcome (Figure S2, Supplementary Materials). Heterogeneity was not significant $\left(\mathrm{I}^{2}=0 \%, p=0.68\right)$.

\subsubsection{Intrauterine Growth Restriction (IUGR)}

We found nine trials that compared the effect of omega 3 supplements versus placebo or versus compounds without omega 3 on the IUGR rate. The review included 10,467 patients: the experimental group included 5237 participants, of whom 595 had IUGR, and the control group included 5230 participants, of whom we found that 575 had IUGR (Figure S3, Supplementary Materials). According to these results, there were no differences in the risk of IUGR (RR, $1.04 ; 95 \% \mathrm{CI}, 0.92$ to 1.18$)$. Heterogeneity was not significant $\left(\mathrm{I}^{2}=0 \%\right.$, $p=0.76)$.

\subsubsection{Fetal Death}

We found 17 trials that compared the effect of omega 3 supplements versus placebo or versus compounds without omega 3 on the rate of intrauterine fetal death (IUFD). The review included 17,517 patients: the experimental group included 9647 participants, 74 with IUFD, and 7870 control participants, of whom we found 54 with IUFD (Figure S4, Supplementary Materials). According to these results, there were no differences in the risk of IUFD (RR, $1.20 ; 95 \%$ CI, 0.85 to 1.69). No asymmetry was observed in the funnel plot's visual evaluation for this outcome (Figure S5, Supplementary Materials). Heterogeneity was not significant $\left(\mathrm{I}^{2}=0 \%, p=0.93\right)$.

\subsubsection{Neonatal Death}

We identified ten trials that compared the effect of omega 3 supplements versus placebo or versus compounds without omega 3 on the neonatal death rate. The review included a total of 16,066 patients: the experimental group included 8921 participants, of whom 30 experienced neonatal death, and the control group included 7145 participants, of whom 32 experienced neonatal death (Figure S6, Supplementary Materials). According to these results, there were no differences in neonatal death risk (RR, $0.81 ; 95 \% \mathrm{CI}, 0.50$ to 1.34). No asymmetry was observed in the funnel plot's visual evaluation for this outcome (Figure S7, Supplementary Materials). Heterogeneity was not significant $\left(\mathrm{I}^{2}=0 \%, p=0.79\right)$.

\subsection{Sensitivity Analysis}

We performed sensitivity analyses to explore the effects of trial quality, including only articles considered low risk for random sequence generation, allocation concealment and blinding of participants and personnel. We restricted the sensitivity analysis to the outcome of PTB (main outcome, 15 out of 37 studies) and ePTB (7 out of 11 studies). According to this analysis, there were no significant differences in PTB risk between the group supplemented with omega 3 and the control group (RR, 0.92; 95\% CI, 0.83 to 1.01 ). The results of the analysis are summarized in Figure 6. We also did not find statistically significant differences for the risk of ePTB (RR, $0.82 ; 95 \% \mathrm{CI}, 0.61$ to 1.09 ). The results are summarized in Figure 7. 


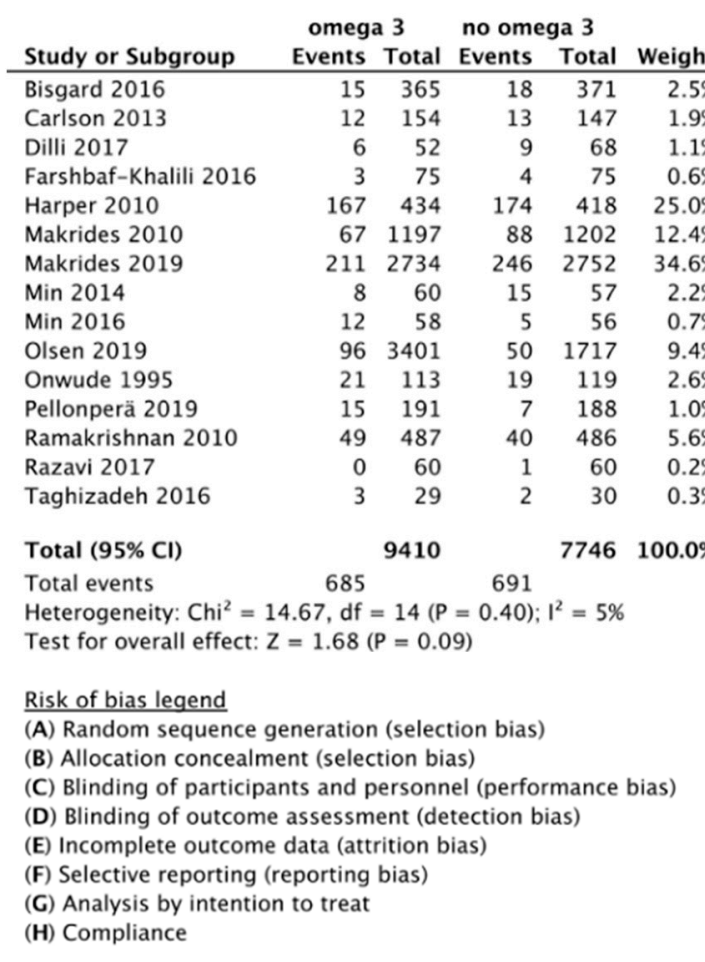

Risk Ratio

$\mathrm{M}-\mathrm{H}$, Fixed, 95\% $\mathrm{Cl}$ $0.85[0.43,1.65]$

$0.88[0.42,1.87]$

$0.87[0.33,2.29]$

$0.75[0.17,3.24]$

$0.92[0.78,1.09]$

$0.76[0.56,1.04]$

$0.86[0.72,1.03]$

$0.51[0.23,1.10]$

$2.32[0.87,6.15]$

$0.97[0.69,1.36]$

$1.16[0.66,2.05]$

$1.16[0.66,2.05]$
$2.11[0.88,5.06]$

$1.22[0.82,1.82]$

$0.33[0.01,8.02]$

$0.33[0.01,8.02]$
$1.55[0.28,8.62]$

$0.92[0.83,1.01]$

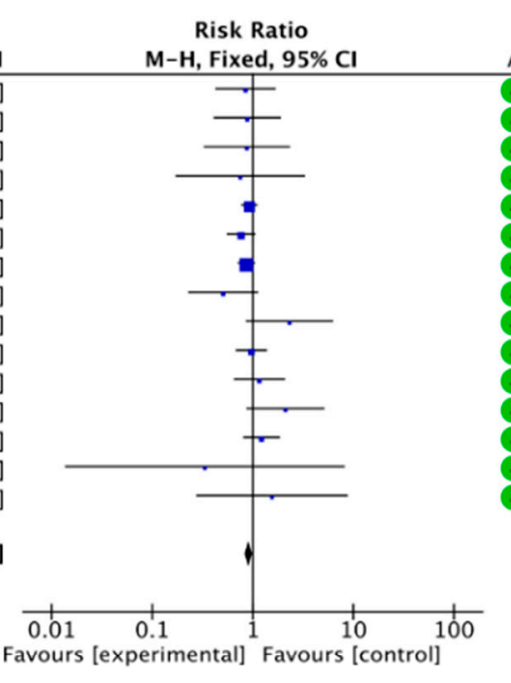

Risk of Bias A B C D E F G H A B C D E F G H

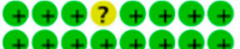
$\stackrel{+}{+}+$ ?

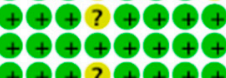
$+\hookrightarrow$ ?

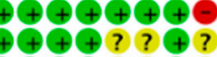
$\hookrightarrow+\hookrightarrow$ ? ? ? ?

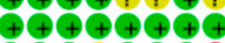

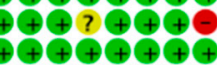

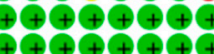

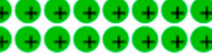

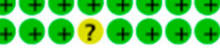

Figure 6. Forest plot of comparison: Sensitivity analysis, outcome: preterm birth ( $<37$ weeks of gestation).

\begin{tabular}{|c|c|c|c|c|c|}
\hline \multirow[b]{2}{*}{ Study or Subgroup } & \multicolumn{2}{|c|}{ omega 3} & \multicolumn{2}{|c|}{ no omega 3} & \multirow[b]{2}{*}{ Weigr } \\
\hline & Events & Total & Events & Total & \\
\hline Carlson 2013 & 1 & 154 & 7 & 147 & \\
\hline Farshbaf-Khalili 2016 & 0 & 75 & 0 & 75 & \\
\hline Harris 2015 & 4 & 240 & 7 & 129 & \\
\hline Makrides 2010 & 13 & 1197 & 27 & 1202 & \\
\hline Makrides 2019 & 61 & 2734 & 55 & 2752 & \\
\hline Min 2014 & 4 & 60 & 4 & 57 & \\
\hline Min 2016 & 2 & 58 & 0 & 56 & \\
\hline Total $(95 \% \mathrm{Cl})$ & \multicolumn{3}{|c|}{4518} & 4418 & 100 \\
\hline Total events & 85 & & 100 & & \\
\hline \multicolumn{6}{|c|}{$\begin{array}{l}\text { Heterogeneity: } \text { Chi }^{2}=12.13, d f=5(P=0.03) ; I^{2}=59 \% \\
\text { Test for overall effect: } Z=1.35(P=0.18)\end{array}$} \\
\hline \multicolumn{6}{|l|}{ Risk of bias legend } \\
\hline \multicolumn{6}{|c|}{$\overline{\text { (A) Random sequence generation (selection bias) }}$} \\
\hline \multicolumn{6}{|c|}{ (B) Allocation concealment (selection bias) } \\
\hline \multicolumn{6}{|c|}{ (C) Blinding of participants and personnel (performance bias) } \\
\hline \multicolumn{6}{|c|}{ (D) Blinding of outcome assessment (detection bias) } \\
\hline \multicolumn{6}{|c|}{ (E) Incomplete outcome data (attrition bias) } \\
\hline \multicolumn{6}{|c|}{ (F) Selective reporting (reporting bias) } \\
\hline \multicolumn{6}{|c|}{ (G) Analysis by intention to treat } \\
\hline (H) Compliance & & & & & \\
\hline
\end{tabular}

Figure 7. Forest plot of comparison: Sensitivity analysis, outcome: early preterm birth (<34 weeks of gestation).

\subsection{Risk of Bias}

The risk of bias of the included trials is summarized in Figures S8 and S9 in the Supplementary Materials, which includes random sequence generation, allocation concealment, blinding of participants and personnel, blinding of outcome assessment, incomplete outcome data and selective reporting. In addition to the risks of bias recommended by Higgins 2011 [20], we evaluated two possible biases that could affect the validity of the articles: intention-to-treat and compliance. We considered that the intention-to-treat princi- 
ple was violated if there was post-randomization exclusion of participants. We considered compliance low risk if it was measured and was greater than $80 \%$.

\section{Discussion}

Preterm delivery is a leading cause of neonatal and childhood mortality and is associated with cognitive deficiencies and increased risk of cardio-metabolic diseases in adult life [21,22]. LC-PUFA are involved in optimum fetoplacental growth and development through their function associated with oxidative stress, angiogenesis and inflammation [23]. The consumption of oily fish and DHA supplements during pregnancy has been associated with maternal and infant benefits, including decreased maternal blood pressure [24] and infant neurodevelopment and growth [25]. Previous studies have explored the relationship between omega 3 intake during pregnancy and timing of delivery or preterm risk; however, the results are still inconsistent. Meanwhile, some clinical trials reported an increase in gestational length after DHA and fish oil supplement interventions [26], and others reported no effect in the incidence of ePTB [27] and PTB [15]. A previous meta-analysis also analyzed the effect of omega 3 supplementation on PTB rates; in 2015, Saccone and Berghella reported no effect of omega 3 with only two RCTs analyzed [28]. However, in 2016, Kar et al., following the analyses of nine studies, did find a positive effect of omega 3 supplementation on the prevention of PTB [29]. Besides including a greater number of studies, compared with Kar and Colleagues, our study provides an update of RCTs published until June 2020 as well as the analyses of secondary outcomes, such as preeclampsia, IUGR and fetal and neonatal death.

Based on the present meta-analysis results, we conclude that omega 3 supplementation during pregnancy does not reduce the risk of PTB and ePTB. Although preliminary results showed that omega 3 supplementation reduced the risk of PTB and ePTB by $11 \%$ and $27 \%$, respectively, after sensitivity analyses were performed and only low risk of bias studies were analyzed, the significance of the effect of omega 3 on PTB and ePTB risk disappears. Concerning the effect of omega 3 supplementation on other perinatal outcomes, such as preeclampsia, IUGR risk and fetal and neonatal death, no differences were found in this study. These results suggest that among the studies analyzed, there is not enough evidence suggesting that omega 3 supplementation during pregnancy decreases the risk of PTB and other perinatal complications.

The form of omega 3 supplementation in the analyzed trials differed and included capsules; liquid fish oil; and enriched food products, such as eggs high in DHA and bars containing DHA. The intake of $600 \mathrm{mg}$ of DHA/day as capsules or bars has shown an increased length of pregnancy by 2.9 days [12] and 4.0-4.5 days [30]; meanwhile, the ingestion of $137 \mathrm{mg}$ of DHA from high-DHA eggs showed a gestation increase of 6 days [26]. It can be hypothesized that food-based DHA (i.e., DHA-rich eggs) might have a more pronounced impact on pregnancy lengths as omega 3 bioavailability is higher when DHA is consumed in a high-fat food matrix [31]. The administration of omega 3 as DHA and EPA by itself or in combination with other nutrients should also be considered at the moment of describing the effect of omega 3 on fetal and maternal outcomes. In this review, considering the number of studies, it was not possible to differentiate between different doses and different components of supplementations. Similarly, nutritional status and omega 3 deficiency should also be considered. Lower levels of plasma EPA and DHA showed a 10-fold increased risk of ePTB compared to the higher plasma levels [8], demonstrating a potential benefit of the supplementation effect during deficiency.

Timing and length of supplementation are important factors determining the effect of omega 3 on preterm delivery risk. Considering the mechanism of action of omega 3 associated with inflammation and electrical activity of myometrium, it can be expected that acute (short-term) and chronic (throughout the pregnancy) supplementation have different effects on outcomes related to preterm delivery. The time of administration, the gestational week when the supplementation started and if the treatment continued through the whole pregnancy or not are characteristics that have to be considered in future studies. 
The potential adverse effects of omega 3 supplementation are not discussed in this review; however, post-term partition or bleeding have been associated with high omega 3 doses (>2.7 g/day) [32].

Furthermore, the strengths and limitations of this study should be considered. Our study's strength is that 37 studies were analyzed, which included a total of 21,458 and 10,864 women for PTB and ePTB risk analyses, respectively. This studies are summarized in Table S2 [10-15,24,26,27,30,33-59]. Although risk of bias was considered in the study, additionally, a sensitivity analysis was performed to assess each publication's reliability. There are, however, some limitations to this study. Firstly, among the studies that met the inclusion criteria and were considered low risk of bias, only 15/31 and 7/11 trials for PTB and ePTB studies, respectively, were included after sensitivity analyses. This selection removed the significant results that were found early in the study. Therefore, more RCTs with high-quality standards may be required to increase the number of RCTs included in the sensitivity analyses. Secondly, the oldest trial analyzed was published in 1992; this may suggest differences in the baseline nutritional status and diet style of the participants compared with the newest RCTs and could generate a higher heterogenicity among demographic and anthropometric characteristics of women. Finally, the type of dose, timing and length of supplementation were not considered in the analysis, which are all aspects that can influence the effect of omega 3 supplementation on PTB prevention.

\section{Conclusions}

In summary, our results suggest that there is not enough available evidence that supports the conclusion that omega 3 supplementation during pregnancy reduces the risk of PTB and ePTB. However, more research is needed to identify the impact of fish oil and omega 3 supplementation on PTB rates.

Supplementary Materials: The following are available online at https:/ /www.mdpi.com/article/ 10.3390/nu13051704/s1, Table S1: Keywords and search strategies; Table S2: Characteristics of randomized controlled trials (RCTs) included in systematic review; Figure S1 Forest plot of comparison: omega 3 vs. No omega 3, outcome: preeclampsia or pregnancy-induced hypertension (PIH); Figure S2: Funnel plot of comparison: omega 3 vs. no omega 3, outcome: preeclampsia or pregnancy-induced hypertension (PIH); Figure S3: Forest plot of comparison: omega 3 vs. no omega 3, outcome: IUGR (<p10); Figure S4: Forest plot of comparison: omega 3 vs. no omega 3, outcome: fetal death; Figure S5: Funnel plot of comparison: omega 3 vs. no omega 3, outcome: fetal death; Figure S6: Forest plot of comparison: omega 3 vs. no omega 3, outcome: neonatal death; Figure S7: Funnel plot of comparison: omega 3 vs. no omega 3, outcome: neonatal death; Figure S8: Risk of bias graph; and Figure S9: Risk of bias summary.

Author Contributions: Conceptualization, R.S., R.P. and S.E.I.; methodology, R.S., R.P. and S.E.I.; software, R.S., R.P. and S.E.I.; formal analysis, R.S., R.P. and S.E.I.; investigation, R.S., M.P., L.M., C.B., G.V. and R.P.; resources, R.S., R.P. and S.E.I.; writing—original draft preparation, R.P., R.S. and S.E.I.; writing—review and editing, R.P., S.E.I., R.S., M.M. and L.J.M.; visualization, R.S., R.P.; supervision, R.S., R.P., M.C. and S.E.I.; project administration, R.S., R.P. and S.E.I. All authors have read and agreed to the published version of the manuscript.

Funding: This work was supported by National Agency for Investigation and Development, ANID: FONDECYT Regular 1201851 to S.E.I.

Institutional Review Board Statement: Not applicable.

Informed Consent Statement: Not applicable.

Data Availability Statement: Not applicable.

Conflicts of Interest: The authors declare no conflict of interest. 


\section{References}

1. Blencowe, H.; Cousens, S.; Oestergaard, M.Z.; Chou, D.; Moller, A.B.; Narwal, R.; Adler, A.; Vera Garcia, C.; Rohde, S.; Say, L.; et al. National, regional, and worldwide estimates of preterm birth rates in the year 2010 with time trends since 1990 for selected countries: A systematic analysis and implications. Lancet 2012, 379, 2162-2172. [CrossRef]

2. Blencowe, H.; Cousens, S.; Chou, D.; Oestergaard, M.; Say, L.; Moller, A.B.; Kinney, M.; Lawn, J. Born Too Soon: The global epidemiology of 15 million preterm births Understanding the data Preterm birth-What is it? Defining preterm birth. Reprod. Health 2013, 10, 1-13. [CrossRef]

3. Adams, M.M.; Elam-Evans, L.D.; Wilson, H.G.; Gilbertz, D.A. Rates of and Factors Associated with Recurrence of Preterm Delivery. Obstet. Gynecol. Surv. 2000, 55, 534-536. [CrossRef]

4. Spong, C.Y. Prediction and Prevention of Recurrent Spontaneous Preterm Birth. Obstet. Gynecol. 2007, 110, 405-415. [CrossRef]

5. Carlson, S.E.; Colombo, J. Docosahexaenoic Acid and Arachidonic Acid Nutrition in Early Development. Adv. Pediatr. 2016, 63, 453-471. [CrossRef] [PubMed]

6. Institute of Medicine. Dietary Reference Intakes for Energy, Carbohydrate, Fiber, Fat, Fatty Acids, Cholesterol, Protein, and Amino Acids; Institute of Medicine: Washington, DC, USA, 2005; ISBN 030908525X.

7. Food and Agriculture Organization FAO. Fats and Fatty Acids in Human Nutrition. Proceedings of the Joint FAO/WHO Expert Consultation; FAO: Rome, Italy, 2008; Volume 55.

8. Olsen, S.F.; Halldorsson, T.I.; Thorne-Lyman, A.L.; Strøm, M.; Gørtz, S.; Granstrøm, C.; Nielsen, P.H.; Wohlfahrt, J.; Lykke, J.A.; Langhoff-Roos, J.; et al. Plasma Concentrations of Long Chain N-3 Fatty Acids in Early and Mid-Pregnancy and Risk of Early Preterm Birth. EBioMedicine 2018, 35, 325-333. [CrossRef]

9. Wadhwani, N.; Patil, V.; Pisal, H.; Joshi, A.; Mehendale, S.; Gupte, S.; Wagh, G.; Joshi, S. Altered maternal proportions of long chain polyunsaturated fatty acids and their transport leads to disturbed fetal stores in preeclampsia. Prostaglandins Leukot. Essent. Fat. Acids 2014, 91, 21-30. [CrossRef] [PubMed]

10. Olsen, S.F.; Secher, N.J.; Tabor, A.; Weber, T.; Walker, J.J.; Gluud, C. Randomised clinical trials of fish oil supplementation in high risk pregnancies. BJOG Int. J. Obstet. Gynaecol. 2000, 107, 382-395. [CrossRef] [PubMed]

11. Borod, E.; Atkinson, R.; Barclay, W.R.; Carlson, S.E. Effects of third trimester consumption of eggs high in docosahexaenoic acid on docosahexaenoic acid status and pregnancy. Lipids 1999, 34, 1999. [CrossRef] [PubMed]

12. Carlson, S.E.; Colombo, J.; Gajewski, B.J.; Gustafson, K.M.; Mundy, D.; Yeast, J.; Georgieff, M.K.; Markley, L.A.; Kerling, E.H.; Shaddy, D.J. DHA supplementation and pregnancy outcomes. Am. J. Clin. Nutr. 2013, 97, 808-815. [CrossRef]

13. Harper, M.; Thom, E.; Klebanoff, M.A.; Thorp, J.; Sorokin, Y.; Varner, M.W.; Wapner, R.J.; Caritis, S.N.; Iams, J.D.; Carpenter, M.W.; et al. Omega-3 fatty acid supplementation to prevent recurrent preterm birth: A randomized controlled trial. Obstet. Gynecol. 2010, 115, 234-242. [CrossRef] [PubMed]

14. Makrides, M.; Gibson, R.A.; McPhee, A.J.; Yelland, L.; Quinlivan, J.; Ryan, P. DOMInO Investigative Team, and the Effect of DHA Supplementation during Pregnancy on Maternal Depression and Neurodevelopment of Young Children. JAMA 2010, $304,1675$. [CrossRef] [PubMed]

15. Olsen, S.F.; Halldorsson, T.I.; Li, M.; Strøm, M.; Mao, Y.; Che, Y.; Wang, Y.; Duan, F.; Olsen, J.; Zhou, W. Examining the Effect of Fish Oil Supplementation in Chinese Pregnant Women on Gestation Duration and Risk of Preterm Delivery. J. Nutr. 2019, 149, 1942-1951. [CrossRef] [PubMed]

16. Mosaad, E.; Peiris, H.N.; Holland, O.; Morean Garcia, I.; Mitchell, M.D. The Role(s) of Eicosanoids and Exosomes in Human Parturition. Front. Physiol. 2020, 11, 594313. [CrossRef]

17. Ishihara, T.; Yoshida, M.; Arita, M. Omega-3 fatty acid-derived mediators that control inflammation and tissue homeostasis. Int. Immunol. 2019, 31, 559-567. [CrossRef] [PubMed]

18. Yamashita, A.; Kawana, K.; Tomio, K.; Taguchi, A.; Isobe, Y.; Iwamoto, R.; Masuda, K.; Furuya, H.; Nagamatsu, T.; Nagasaka, K.; et al. Increased tissue levels of omega-3 polyunsaturated fatty acids prevents pathological preterm birth. Sci. Rep. 2013, 3, 1-7. [CrossRef]

19. Olsen, S.F.; Secher, N.J.; Björnsson, S.; Weber, T.; Atke, A. The potential benefits of using fish oil in relation to preterm labor: The case for a randomized controlled trial? Acta Obstet. Gynecol. Scand. 2003, 82, 978-982. [CrossRef]

20. Higgins, J.P.T.; Altman, D.G.; Gotzsche, P.C.; Juni, P.; Moher, D.; Oxman, A.D.; Savovic, J.; Schulz, K.F.; Weeks, L.; Sterne, J.A.C. The Cochrane Collaboration's tool for assessing risk of bias in randomised trials. BMJ 2011, 343, d5928. [CrossRef]

21. Linsell, L.; Johnson, S.; Wolke, D.; O’Reilly, H.; Morris, J.K.; Kurinczuk, J.J.; Marlow, N. Cognitive trajectories from infancy to early adulthood following birth before 26 weeks of gestation: A prospective, population-based cohort study. Arch. Dis. Child. 2018, 103, 363-370. [CrossRef]

22. Liu, L.; Johnson, H.L.; Cousens, S.; Perin, J.; Scott, S.; Lawn, J.E.; Rudan, I.; Campbell, H.; Cibulskis, R.; Li, M.; et al. Global, regional, and national causes of child mortality: An updated systematic analysis for 2010 with time trends since 2000. Lancet 2012, 379, 2151-2161. [CrossRef]

23. Godhamgaonkar, A.A.; Wadhwani, N.S.; Joshi, S.R. Exploring the role of LC-PUFA metabolism in pregnancy complications. Prostaglandins Leukot. Essent. Fat. Acids 2020, 163, 102203. [CrossRef]

24. Lalooha, F. Evaluation of the effect of omega-3 supplements in the prevention of preeclampsia among high risk women. Afr. J. Pharm. Pharmacol. 2012, 6, 2580-2583. [CrossRef] 
25. Ostadrahimi, A.; Salehi-Pourmehr, H.; Mohammad-Alizadeh-Charandabi, S.; Heidarabady, S.; Farshbaf-Khalili, A. The effect of perinatal fish oil supplementation on neurodevelopment and growth of infants: A randomized controlled trial. Eur. J. Nutr. 2017, 57, 2387-2397. [CrossRef] [PubMed]

26. Smuts, C.M.; Huang, M.; Mundy, D.; Plasse, T.; Major, S.; Carlson, S.E. A randomized trial of docosahexaenoic acid supplementation during the third trimester of pregnancy. Obstet. Gynecol. 2003, 101, 469-479. [CrossRef]

27. Makrides, M.; Best, K.; Yelland, L.; McPhee, A.; Zhou, S.; Quinlivan, J.; Dodd, J.; Atkinson, E.; Safa, H.; van Dam, J.; et al. A Randomized Trial of Prenatal n-3 Fatty Acid Supplementation and Preterm Delivery. N. Engl. J. Med. 2019, 381, 1035-1045. [CrossRef] [PubMed]

28. Saccone, G.; Berghella, V. Omega-3 supplementation to prevent recurrent preterm birth: A systematic review and metaanalysis of randomized controlled trials. Am. J. Obstet. Gynecol. 2015, 213, 135-140. [CrossRef] [PubMed]

29. Kar, S.; Wong, M.; Rogozinska, E.; Thangaratinam, S. Effects of omega-3 fatty acids in prevention of early preterm delivery: A systematic review and meta-analysis of randomized studies. Eur. J. Obstet. Gynecol. Reprod. Biol. 2016, 198, 40-46. [CrossRef] [PubMed]

30. Harris, M.A.; Reece, M.S.; McGregor, J.A.; Wilson, J.W.; Burke, S.M.; Wheeler, M.; Anderson, J.E.; Auld, G.W.; French, J.I.; Allen, K.G.D. The Effect of Omega-3 Docosahexaenoic Acid Supplementation on Gestational Length: Randomized Trial of Supplementation Compared to Nutrition Education for Increasing n-3 Intake from Foods. Biomed Res. Int. 2015, $2015,1-8$. [CrossRef]

31. Cholewski, M.; Tomczykowa, M.; Tomczyk, M. A Comprehensive Review of Chemistry, Sources and Bioavailability of Omega-3 Fatty Acids. Nutrients 2018, 10, 1662. [CrossRef]

32. von Schacky, C. Omega-3 Fatty Acids in Pregnancy-The Case for a Target Omega-3 Index. Nutrients 2020, 12, 898. [CrossRef]

33. Jamilian, M.; Samimi, M.; Mirhosseini, N.; Ebrahimi, F.A.; Aghadavod, E.; Taghizadeh, M.; Asemi, Z. A randomized doubleblinded, placebo-controlled trial investigating the effect of fish oil supplementation on gene expression related to insulin action, blood lipids, and inflammation in gestational diabetes mellitus-fish oil supplementation and gestation. Nutrients 2018, 10, 163. [CrossRef]

34. Bisgaard, H.; Stokholm, J.; Chawes, B.L.; Vissing, N.H.; Bjarnadóttir, E.; Schoos, A.-M.M.; Wolsk, H.M.; Pedersen, T.M.; Vinding, R.K.; Thorsteinsdóttir, S.; et al. Fish Oil-Derived Fatty Acids in Pregnancy and Wheeze and Asthma in Offspring. N. Engl. J. Med. 2016, 375, 2530-2539. [CrossRef] [PubMed]

35. Bulstra-Ramakers, M.T.E.W.; Huisjes, H.J.; Visser, G.H.A. The effects of $3 g$ eicosapentaenoic acid daily on recurrence of intrauterine growth retardation and pregnancy induced hypertension. BJOG Int. J. Obstet. Gynaecol. 1994, 102, 123-126. [CrossRef] [PubMed]

36. D'Almeida, A.; Carter, J.P.; Anatol, A.; Prost, C. Effects of a Combination of Evening Primrose Oil (Gamma Linolenic Acid) and Fish Oil (Eicosapentaenoic + Docahexaenoic Acid) versus Magnesium, and versus Placebo in Preventing Pre-Eclampsia. Women Health 1992, 19, 117-131. [CrossRef] [PubMed]

37. De Groot, R.H.M.; Hornstra, G.; Van Houwelingen, A.C.; Roumen, F. Effect of $\alpha$-linolenic acid supplementation during pregnancy on maternal and neonatal polyunsaturated fatty acid status and pregnancy outcome. Am. J. Clin. Nutr. 2004, 79, 251-260. [CrossRef]

38. Dilli, D.; Doğan, N.N.; İpek, M.Ş.; Çavuş, Y.; Ceylaner, S.; Doğan, H.; Dursun, A.; Küçüközkan, T.; Zenciroğlu, A. MaFOS-GDM trial: Maternal fish oil supplementation in women with gestational diabetes and cord blood DNA methylation at insulin like growth factor-1 (IGF-1) gene. Clin. Nutr. ESPEN 2017, 23, 73-78. [CrossRef]

39. Haghiac, M.; Yang, X.H.; Presley, L.; Smith, S.; Dettelback, S.; Minium, J.; Belury, M.A.; Catalano, P.M.; Hauguel-De Mouzon, S. Dietary omega-3 fatty acid supplementation reduces inflammation in obese pregnant women: A randomized double-blind controlled clinical trial. PLoS ONE 2015, 10, 1-14. [CrossRef] [PubMed]

40. Hauner, H.; Much, D.; Vollhardt, C.; Brunner, S.; Schmid, D.; Sedlmeier, E.M.; Heimberg, E.; Schuster, T.; Zimmermann, A.; Schneider, K.T.M.; et al. Effect of reducing the n-6:n-3 long-chain PUFA ratio during pregnancy and lactation on infant adipose tissue growth within the first year of life: An open-label randomized controlled trial. Am. J. Clin. Nutr. 2012, 95, 383-394. [CrossRef]

41. Helland, I.B.; Saugstad, O.D.; Smith, L.; Saarem, K.; Solvoll, K.; Ganes, T.; Drevon, C.A. Similar effects on infants of n-3 and n-6 fatty acids supplementation to pregnant and lactating women. Pediatrics 2001, 108. [CrossRef]

42. Horvaticek, M.; Djelmis, J.; Ivanisevic, M.; Oreskovic, S.; Herman, M. Effect of eicosapentaenoic acid and docosahexaenoic acid supplementation on C-peptide preservation in pregnant women with type-1 diabetes: Randomized placebo controlled clinical trial. Eur. J. Clin. Nutr. 2017, 71, 968-972. [CrossRef]

43. Taghizadeh, M.; Jamilian, M.; Mazloomi, M.; Sanami, M.; Asemi, Z. A randomized-controlled clinical trial investigating the effect of omega-3 fatty acids and Vitamin E co-supplementation on markers of insulin metabolism and lipid profiles in gestational diabetes. J. Clin. Lipidol. 2016, 10, 386-393. [CrossRef]

44. Farshbaf-Khalili, A.; Mohammad-Alizadeh, S.; Farshbaf-Khalili, A.; Mohammadi, F.; Ostadrahimi, A. Fish-Oil Supplementation and Maternal Mental Health: A Triple-Blind, Randomized Controlled Trial. Iran. Red Crescent Med. J. 2016, 19. [CrossRef]

45. Malcolm, C.A.; Hamilton, R.; McCulloch, D.L.; Montgomery, C.; Weaver, L.T. Scotopic Electroretinogram in Term Infants Born of Mothers Supplemented with Docosahexaenoic Acid during Pregnancy. Investig. Opthalmology Vis. Sci. 2003, 44, 3685. [CrossRef] [PubMed] 
46. Mardones, F.; Urrutia, M.-T.; Villarroel, L.; Rioseco, A.; Castillo, O.; Rozowski, J.; Tapia, J.-L.; Bastias, G.; Bacallao, J.; Rojas, I. Effects of a dairy product fortified with multiple micronutrients and omega-3 fatty acids on birth weight and gestation duration in pregnant Chilean women. Public Health Nutr. 2007, 11, 30-40. [CrossRef]

47. Miller, S.; Harris, M.A.; Baker, S.; Davalos, D.; Clark, A.; Mc Girr, K. Intake of Total Omega-3 Docosahexaenoic Acid Associated with Increased Gestational Length and Improved Cognitive Performance at 1 Year of Age. J. Nutr. Health Food Eng. 2016, 5, 642-651. [CrossRef]

48. Min, Y.; Djahanbakhch, O.; Hutchinson, J.; Bhullar, A.S.; Raveendran, M.; Hallot, A.; Eram, S.; Namugere, I.; Nateghian, S.; Ghebremeskel, K. Effect of docosahexaenoic acid-enriched fish oil supplementation in pregnant women with type 2 diabetes on membrane fatty acids and fetal body composition-double-blinded randomized placebo-controlled trial. Diabet. Med. 2014, 31, 1331-1340. [CrossRef] [PubMed]

49. Min, Y.; Djahanbakhch, O.; Hutchinson, J.; Eram, S.; Bhullar, A.S.; Namugere, I.; Ghebremeskel, K. Efficacy of docosahexaenoic acid-enriched formula to enhance maternal and fetal blood docosahexaenoic acid levels: Randomized double-blinded placebocontrolled trial of pregnant women with gestational diabetes mellitus. Clin. Nutr. 2016, 35, 608-614. [CrossRef]

50. Mozurkewich, E.; Clinton, C.; Chilimigras, J.; Hamilton, S.; Allbaugh, L.; Berman, D.; Marcus, S.; Vazquez, D.; Romero, V.; Treadwell, M.; et al. The Mothers, Omega-3 \& Mental Health Study: A double-blind, randomized controlled trial. Am. J. Obstet. Gynecol. 2013, 208, S19-S20. [CrossRef]

51. Olsen, S.F.; Sørensen, J.D.; Secher, N.J.; Hedegaard, M.; Brink Henriksen, T.; Hansen, H.S.; Grant, A. Randomised controlled trial of effect of fish-oil supplementation on pregnancy duration. Lancet 1992, 339, 1003-1007. [CrossRef]

52. Onwude, J.L.; Lilford, R.J.; Hjartardottir, H.; Staines, A.; Tuffnell, D. A randomised double blind placebo controlled trial of fish oil in high risk pregnancy. BJOG Int. J. Obstet. Gynaecol. 1995, 102, 95-100. [CrossRef] [PubMed]

53. Pellonperä, O.; Mokkala, K.; Houttu, N.; Vahlberg, T.; Koivuniemi, E.; Tertti, K.; Rönnemaa, T.; Laitinen, K. Efficacy of fish oil and/or probiotic intervention on the incidence of gestational diabetes mellitus in an at-risk group of overweight and obese women: A randomized, placebo-controlled, double-blind clinical trial. Diabetes Care 2019, 42, 1009-1017. [CrossRef]

54. Ramakrishnan, U.; Stein, A.D.; Parra-Cabrera, S.; Wang, M.; Imhoff-Kunsch, B.; Juárez-Márquez, S.; Rivera, J.; Martorell, R. Effects of docosahexaenoic acid supplementation during pregnancy on gestational age and size at birth: Randomized, double-blind, placebo-controlled trial in Mexico. Food Nutr. Bull. 2010, 31, 108-116. [CrossRef]

55. Razavi, M.; Jamilian, M.; Samimi, M.; Afshar Ebrahimi, F.; Taghizadeh, M.; Bekhradi, R.; Seyed Hosseini, E.; Haddad Kashani, H.; Karamali, M.; Asemi, Z. The effects of Vitamin D and omega-3 fatty acids co-supplementation on biomarkers of inflammation, oxidative stress and pregnancy outcomes in patients with gestational diabetes. Nutr. Metab. 2017, 14, 1-9. [CrossRef] [PubMed]

56. Smuts, C.M.; Borod, E.; Peeples, J.M.; Carlson, S.E. High-DHA eggs: Feasibility as a means to enhance circulating DHA in mother and infant. Lipids 2003, 38, 407-414. [CrossRef] [PubMed]

57. Soldo, D.; Mikulić-Kajić, M.; Spalldi Barišić, L.; Penava, N.; Orlović, M.; Soldo, N.; Kajić, M. Effect of n-3 long-chain polyunsaturated fatty acids supplementation in healthy mothers on DHA and EPA profiles in maternal and umbilical blood: A randomized controlled trial. J. Perinat. Med. 2018, 47, 200-206. [CrossRef]

58. Tofail, F.; Kabir, I.; Hamadani, J.D.; Chowdhury, F.; Yesmin, S.; Mehreen, F.; Huda, S.N. Supplement of fish-oil and soy-oil during pregnancy and psychomotor development of infants. J. Health Popul. Nutr. 2006, 24, 48-56. [CrossRef] [PubMed]

59. Van Goor, S.A.; Dijck-Brouwer, D.A.J.; Hadders-Algra, M.; Doornbos, B.; Erwich, J.J.H.M.; Schaafsma, A.; Muskiet, F.A.J. Human milk arachidonic acid and docosahexaenoic acid contents increase following supplementation during pregnancy and lactation. Prostaglandins Leukot. Essent. Fat. Acids 2009, 80, 65-69. [CrossRef] 